\title{
SYNCOPE CAUSED BY VENTRICULAR TACHYCARDIA AS A CONSEQUENCE MYOCARDIAL ISCHEMIA - THE CASE REPORT
}

\author{
Saša Ignjatijević ${ }^{1}$, Miomir Randjelović ${ }^{2}$ \\ Emergency Medical Centre, Niš, Serbia ${ }^{1}$ \\ Cardiology Clinic, Clinical Centre Niš, Serbia² \\ Contact: Saša Ingnjatijević \\ Emergensy Medical Centar, Niš \\ Vojislava Ilića b.b., 18000 Niš, Serbia \\ E-mail: siscrat@gmail.com
}

Syncope, one of the forms of loss of consciousness, occurs because of the general hypoperfusion of the cerebral cortex caused by reduced arterial pressure. Cardiogenic syncopes occur due to structural heart changes or disrhythmia.

An elderly man experienced syncope in the street. Due to a previous loss of consciousness he was wearing a holter. Medical emergency team found him conscious with normal ECG and vital parameters.

After observation at the Emergency Centre he was referred to a cardiologist with normal physical examination results and without any complaints. Cardiologist admitted him to hospital because of the ECG changes.

Coronography performed next day showed a significant stricture in the branches of the left coronary artery and four stents were placed. Holter monitoring after the stent place ment did not show any rhythm disorders. Holter monitoring that patient was wearing at the moment of his loss of consciousness, showed episodes of ventricular tachycardia preceded by myocardial ischemia. After revascularization, patient was referred to the Institute for Treatment and Rehabilitation „Niška Banja".

Timely diagnosis and adequate therapy for syncope of cardiogenic origin could prevent severe consequences, the most serious of which is sudden death. Acta Medica Medianae 2017;56(2):38-44.

Key words: Syncope, Miocardial Ischemia, Tachycardia, Ventricular 